Arnaud W. Thille

Alain Vuylsteke

Andrew Bersten

\section{Does the Berlin definition for acute respiratory distress syndrome predict the presence of diffuse alveolar damage?}

Received: 12 December 2014

Accepted: 15 December 2014

Published online: 8 January 2015

(C) Springer-Verlag Berlin Heidelberg and ESICM 2014

\section{A. W. Thille ( $)$}

Réanimation Médicale, CHU de Poitiers, 2 Rue la Milétrie, 86021 Poitiers Cedex, France

e-mail: aw.thille@gmail.com

Tel.: 0033549444367

A. W. Thille

INSERM, CIC 1402, Université de Poitiers, Poitiers, France

A. Vuylsteke

Papworth Hospital NHS Foundation Trust, Cambridge, UK

\section{A. Bersten}

Flinders University and Flinders Medical Centre,

Adelaide, SA, Australia

Guérin et al. retrospectively examined all open lung biopsies (OLB) performed in patients with non-resolving acute respiratory distress syndrome (ARDS), without an identified cause [1]. Eighty-three of the 113 patients who underwent OLB over a 16-year period (1998-2013) met the clinical criteria for ARDS according to the Berlin definition [2, 3], which represents $14 \%$ of all patients they diagnosed with ARDS over that period (83/597). Does this report help address the relevance of OLB for management of ARDS today?

The authors' main objective was to assess the proportion of patients with diffuse alveolar damage (DAD); they observed that $58 \%$ of patients with ARDS (48/83) had hallmark signs of DAD. These findings are similar to those reported by Thille et al. from postmortem reports
[4], where DAD was present in $56 \%(118 / 229)$ of patients who met ARDS clinical criteria for longer than $72 \mathrm{~h}$. In both studies, the authors also reported the distribution of DAD according to the ARDS severity. While these proportions were similar (see the table in Fig. 1) statistical significance was only achieved in the paper by Thille et al. possibly owing to greater statistical power. This means that the Berlin definition has a low specificity to predict DAD [4]. In other words, a high proportion of patients will meet the Berlin definition criteria for ARDS without DAD on histological examination. The clinician will want to know if this helps to address the relevance of OLB in these complex patients.

DAD is regarded as the morphological hallmark of the lung in ARDS and is defined by the presence of hyaline membranes [5, 6]. These may take 2-3 days to appear [5] and this explains a lower incidence of DAD if the lungs are examined within the first 3 days [4]. The initial, exudative phase is characterized by capillary congestion and intra-alveolar edema, and is maximal in the early course of ARDS, and subsequently followed by alveolar type I cell necrosis. The later repair phase is characterized by intense proliferation of alveolar type II cells and interstitial fibroblasts $[5,6]$. This sequence of histological lesions has been described in patients with ARDS meeting the Berlin definition [7]. Proliferative changes occur early in the course of ARDS and are identified in more than half of the patients during the first week, while fibrosis is observed as early as the second week [7]. This strongly suggests that research on the efficacy of steroids, antiinflammatory, or other anti-fibroproliferative agents should target the first week after ARDS onset, and probably underlies why the use of steroids is not recommended in non-resolving ARDS. Beneficial outcomes related to early steroid therapy have been published $[8,9]$ but secondary analysis of a large randomized controlled study showed an increase in mortality if steroid therapy was initiated after 2 weeks of evolution [10]. The OLB 


\begin{tabular}{|c|c|c|c|c|c|c|}
\hline \multirow{3}{*}{$\begin{array}{l}\text { Study } \\
\text { Reference }\end{array}$} & \multirow{3}{*}{$\begin{array}{c}\text { Type of Histological } \\
\text { Examination }\end{array}$} & \multirow{2}{*}{\multicolumn{4}{|c|}{$\begin{array}{c}\text { Incidence of DAD according to } \\
\text { the severity of ARDS (\%) }\end{array}$}} & \multirow{3}{*}{$\begin{array}{c}P \\
\text { value }\end{array}$} \\
\hline & & & & & & \\
\hline & & Overall & Mild & Moderate & Severe & \\
\hline Guérin et al. [1] & Open lung biopsies & $58 \%(48 / 83)$ & $36 \%(4 / 11)$ & $59 \%(33 / 56)$ & $69 \%(11 / 16)$ & 0.23 \\
\hline Thille et al. [4] & Clinical autopsies & $56 \%(118 / 229)$ & $14 \%(4 / 28)$ & $52 \%(45 / 87)$ & $69 \%(79 / 114)$ & $<0.01$ \\
\hline
\end{tabular}

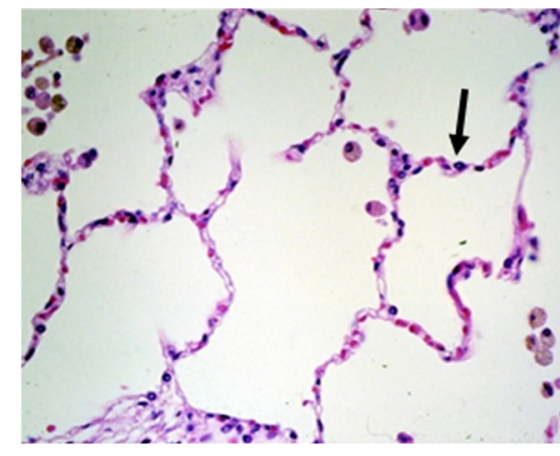

Fig. 1 The table shows the proportion of patients with diffuse alveolar damage (DAD) on histological examination according to the severity of acute respiratory distress syndrome (ARDS) in the study by Guérin et al. [1] and in a database of clinical autopsies [4]. The left panel shows normal lung tissue characterized by a thin alveolar-capillary membrane (arrow) separating red blood cells from the alveolar space, and including endothelial cell, basal membrane, and epithelial cell. The middle panel shows typical histological findings of DAD with hyaline membranes (arrow) covering the denuded basal membrane and necrosis of alveolar type

obtained in non-resolving ARDS will be too late for those patients with DAD as the appropriate time to initiate therapies will have lapsed. With this in mind, the main objective of OLB in non-resolving ARDS would be to detect other histological patterns than DAD.

Perhaps the low specificity of the Berlin definition to detect DAD is explained by the presence of other processes, with a similar clinical picture, but not identical pathological features that are potentially responsive to treatment and will be identified by an OLB (see Fig. 1). These include bacterial or viral pneumonia, organizing or diffuse interstitial pneumonia, alveolar hemorrhage, lymphangitis, or cancer infiltration. In the study by Guérin et al., OLB were performed 9 days (in median) after the onset of ARDS, after having ruled out cardiogenic pulmonary edema or ongoing lung infection using bronchoalveolar lavage, and these unsuspected etiologies without DAD still represented $42 \%$ of the patients with non-resolving ARDS [1]. Bronchoalveolar lavage is a central investigation targeting the cause of ARDS; it enables early identification of bacterial, viral, or fungal pneumonia, and several non-infectious pulmonary etiologies that may mimic ARDS and may respond to steroids such as alveolar hemorrhage due to vasculitis, drug-induced pulmonary toxic pneumonia with a lymphocytic pattern, or an acute eosinophilic pneumonia.

One could argue that the high proportion of organizing pneumonia $(9 / 83,11 \%)$ discovered at OLB is highly relevant as the use of steroids could be particularly effective for those patients [11]. However, this feature could be seen on high-resolution chest computed tomographic scanners, a much less invasive approach than OLB. Similarly, the use of polymerase chain reaction or immunologic assay is likely to improve identification of viral pneumonia or immunologic disorders in a less invasive manner. In 2007, Papazian et al. reported the usefulness of OLB when analyzing 100 patients with nonresolving ARDS [12], mainly because of the identification of cytomegalovirus pneumonia leading to the administration of an antiviral agent. The same investigators showed a few years later that the use of rapid virologic diagnostic tests such as antigenemia or polymerase chain reaction allowed the detection of active cytomegalovirus infection in a high number of mechanically ventilated 
patients [13]. Consequently, improved imaging and diagnostic testing have reduced many of the benefits that OLB has previously offered.

While Guérin et al. assessed the sensitivity and specificity of DAD to predict ARDS [1], the bedside physician may be more interested in looking at this from the opposite perspective. Of note, a significant proportion of patients without ARDS who had OLB were found to have DAD, suggesting caution when we view the Berlin definition as the hallmark of ARDS.

Sharing the data accumulated over the years in their institution is important and might have helped us to understand ARDS better, but whether or not the clinical criteria of ARDS are really useful to identify patients with DAD or another histological pattern remains unanswered. The fact that the data collected by Guerin et al. span many years does not account for the new diagnostic techniques that we believe will decrease the proportion of nonresolving ARDS with a non-identified cause.

Conflicts of interest The authors declare having no potential conflict of interest in relation to this manuscript.

\section{References}

1. Guerin C, Bayle F, Leray V, Debord S, Stoian A, Yonis H et al (2015) Open lung biopsy in non-resolving ARDS frequently identifies diffuse alveolar damage regardless of the severity stage and may have implications for patient management. Intensive Care Med. doi: 10.1007/s00134-014-3583-2

2. The ARDS Definition Task Force (2012) Acute respiratory distress syndrome: the Berlin definition. JAMA 307:2526-2533

3. Ferguson N, Fan E, Camporota L, Antonelli M, Anzueto A, Beale R, Brochard L, Brower R, Esteban A, Gattinoni L, Rhodes A, Slutsky A, Vincent J, Rubenfeld G, Thompson B, Ranieri V (2012) The Berlin definition of ARDS: an expanded rationale, justification, and supplementary material. Intensive Care Med 38:1573-1582

4. Thille AW, Esteban A, FernandezSegoviano P, Rodriguez JM, Aramburu JA, Penuelas O, Cortes-Puch I, Cardinal-Fernandez P, Lorente JA, Frutos-Vivar F (2013) Comparison of the Berlin definition for acute respiratory distress syndrome with autopsy. Am J Respir Crit Care Med 187:761-767
5. Katzenstein AL, Bloor CM, Leibow AA (1976) Diffuse alveolar damage-the role of oxygen, shock, and related factors. A review. Am J Pathol 85:209-228

6. Tomashefski JF Jr (2000) Pulmonary pathology of acute respiratory distress syndrome. Clin Chest Med 21:435-466

7. Thille AW, Esteban A, FernandezSegoviano P, Rodriguez JM, Aramburu JA, Vargas-Errazuriz P, Martin-Pellicer A, Lorente JA, Frutos-Vivar F (2013) Chronology of histological lesions in acute respiratory distress syndrome with diffuse alveolar damage: a prospective cohort study of clinical autopsies. Lancet Respir Med 1:395-401

8. Meduri GU, Golden E, Freire AX, Taylor E, Zaman M, Carson SJ, Gibson M, Umberger R (2007)

Methylprednisolone infusion in early severe ARDS: results of a randomized controlled trial. Chest 131:954-963

9. Meduri GU, Headley AS, Golden E, Carson SJ, Umberger RA, Kelso T, Tolley EA (1998) Effect of prolonged methylprednisolone therapy in unresolving acute respiratory distress syndrome: a randomized controlled trial. JAMA 280:159-165
10. Steinberg KP, Hudson LD, Goodman RB, Hough CL, Lanken PN, Hyzy R, Thompson BT, Ancukiewicz M, National Heart, Lung, Blood Institute Acute Respiratory Distress Syndrome Clinical Trials Network (2006) Efficacy and safety of corticosteroids for persistent acute respiratory distress syndrome. N Engl J Med 354:1671-1684

11. Epler GR (2001) Bronchiolitis obliterans organizing pneumonia. Arch Intern Medicine 161:158-164

12. Papazian L, Doddoli C, Chetaille B, Gernez Y, Thirion X, Roch A, Donati Y, Bonnety M, Zandotti C, Thomas P (2007) A contributive result of openlung biopsy improves survival in acute respiratory distress syndrome patients. Crit Care Med 35:755-762

13. Chiche L, Forel JM, Roch A, Guervilly C, Pauly V, Allardet-Servent J, Gainnier M, Zandotti C, Papazian L (2009) Active cytomegalovirus infection is common in mechanically ventilated medical intensive care unit patients. Crit Care Med 37:1850-1857 